\title{
Differential Pharmacological Regulation of Sensorimotor Gating Deficit in CBI Knockout Mice and Associated Neurochemical and Histological Alterations
}

\author{
Antonio Ortega-Álvaro', Francisco Navarrete ${ }^{2,3}$, Auxiliadora Aracil-Fernández ${ }^{2,3}$, Daniela Navarro ${ }^{4}$, \\ Pere Berbel ${ }^{4}$ and Jorge Manzanares*,2,3 \\ 'Laboratori de Neurofarmacologia, Departament de Ciències Experimentals i de la Salut, Universitat Pompeu Fabra, Barcelona, Spain; ${ }^{2}$ Instituto \\ de Neurociencias, Universidad Miguel Hernández-CSIC, Alicante, Spain; ${ }^{3}$ Red Temática de Investigación Cooperativa en Salud (RETICS-Trastornos \\ Adictivos), Instituto de Salud Carlos III, MICINN and FEDER, Madrid, Spain; ${ }^{4}$ Departamento de Histología y Anatomía, Universidad Miguel \\ Hernández, Alacant, Spain,
}

\begin{abstract}
The endocannabinoid system has been widely involved in the pathophysiology of sensorimotor gating deficits. This study aimed to evaluate the pharmacological modulation of the sensorimotor gating impairment induced by cannabinoid CBI receptor (CBIr) deletion. For this purpose, the prepulse inhibition (PPI) paradigm was used to evaluate the effect of two antipsychotics drugs (risperidone and haloperidol) and a psychostimulant (methylphenidate) on the preattentional deficit presented by CBIKO mice. Furthermore, the effects of the CBIr antagonist AM25I on PPI were evaluated in WT mice. Real-time PCR and immunohistochemical studies were carried out to analyze dopamine transporter (DAT) and $\alpha-2 C$ adrenergic receptor (ADRA2C) gene expressions and the distribution of parvalbumin (PV) and cholecystokinin-8 (CCK) immunoreactive (ir) cortical neurons, respectively. Neither risperidone nor haloperidol significantly modified the PPI of WT and CBIKO mice, whereas methylphenidate improved the preattentional deficit of CBIKO mice. In addition, treatment with AM25I (3 mg/kg; i.p.) significantly decreased the PPI of WT animals. The administration of methylphenidate increased DAT and ADRA2C gene expressions in CBIKO mice without producing any effect in WT animals. Immunohistochemical studies revealed that there were no significant changes in CCK immunolabeling between WT and CBIKO mice, whereas the radial distribution of PV-ir neurons was abnormal in CBIKO mice. These data further support the important role of CBIr in sensorimotor gating regulation and the therapeutic usefulness of methylphenidate for the treatment of psychiatric disorders with associated preattentional deficits.

Neuropsychopharmacology (20I5) 40, 2639-2647; doi:I 0.I038/npp.20I5.II3; published online 27 May 2015
\end{abstract}

\section{INTRODUCTION}

The involvement of the endogenous cannabinoid system in the regulation of sensorimotor gating has been explored through genetic and pharmacological approaches, employing the prepulse inhibition (PPI) paradigm to evaluate preattentional deficits. Several studies in animal models have demonstrated that the prolonged activation of cannabinoid CB1 receptors (CB1r) with $\Delta$-9-tetrahydrocannabinol (THC) or synthetic agonists (CP-55,940 and WIN-55,212-2) induces a PPI disruption that is reversed by $\mathrm{CB} 1 \mathrm{r}$ antagonists, pointing out a CB1r-mediated mechanism (Malone and Taylor, 2006; Martin et al, 2003; Schneider and Koch, 2002). In addition, Cannabis sativa consumption in humans has been widely

\footnotetext{
*Correspondence: Dr J Manzanares, Instituto de Neurociencias, Universidad Miguel Hernández-CSIC, Avda. Ramón y Cajal s/n, San Juan de Alicante, Alicante 03550, Spain, Tel: +34 96 591 9252, E-mail: jmanzanares@umh.es

Received 9 December 2014; revised 21 March 2015; accepted 15 April 2015; accepted article preview online 21 April 2015
}

associated with sensorimotor gating impairments closely related with the development of psychotic symptoms (Kedzior and Martin-Iverson, 2006; Rubino and Parolaro, 2014).

Sensorimotor gating impairment is one of the core symptoms with a high incidence and prevalence in schizophrenia. This psychiatric disease is a chronic, severe, and disabling brain disorder characterized by positive, negative, and cognitive symptoms (Strauss, 1993). Several studies have related CB1r with schizophrenia. A biallelic polymorphism found in the first exon of the CNR1 gene suggests an association between this gene variant and schizophrenia depending on the co-occurrence of drug abuse (Leroy et al, 2001). Autoradiographic analysis of post-mortem brain tissue from schizophrenic patients revealed an increase in [3H]SR141716A-specific binding to CB1r in the anterior cingulate cortex (Zavitsanou et al, 2004). In addition, the immunodensity of CB1r was significantly decreased in the frontal cortex of antipsychotic-treated subjects with schizophrenia, but not in drug-free subjects, that could be related 
with the antipsychotic-mediated normalization effect of cognitive function in these patients (Uriguen et al, 2009). On the other hand, deficits in PPI have also been related with other psychiatric disorders such as obsessive compulsive disorder (OCD), Gilles de la Tourette's syndrome, or bipolar disorder (Kohl et al, 2013). However, there is no consensus about relating a preattentional deficit with attention deficit and hyperactivity disorder (ADHD). PPI does not appear to be affected in studies for people with ADHD for children (Castellanos et al, 1996; Ornitz et al, 1992, 1999) and adults (Conzelmann et al, 2010; Feifel et al, 2009; Hanlon et al, 2009) diagnosed with ADHD, but there are other publications in which a PPI disruption is observed in ADHD patients. For instance, Schulz-Juergensen et al (2014) showed a preattentional deficit in ADHD patients that was reversed by methylphenidate treatment. In addition, very recently a clinical trial started in Israel with the purpose of evaluating whether the PPI test of acoustic startle response may result in an objective marker of attention deficit disorder in children and adolescents (ClinicalTrials.gov Identifier: NCT02344784). A critical point to evaluate whether sensorimotor gating is impaired in ADHD depends on the time interval between the prepulse signal and the onset of the startling stimulus. In general, there is an agreement to consider that PPI measures preattention with short intervals (Dawson et al, 1993; Gomes et al, 2014), whereas with longer interstimulus intervals an attentional modulation may occur (Heekeren et al, 2004; Swerdlow et al, 2001). Future studies are encouraged to further evaluate whether ADHD is associated with a preattentional deficit.

Animal models with good face and predictive validity may be useful for investigations of the underlying biological substrates of sensorimotor gating. As our knowledge about the neurobiology of preattentional deficit-related disorders from human studies is limited, it is quite difficult to decide which model best represents the PPI disruption of a specific psychiatric disorder. Recently, we used a phenotype-based approach in $\mathrm{CB} 2 \mathrm{r}$ knockout (CB2KO) mice to explore the role of the CNR2 gene in a particular phenotype related to schizophrenia because of the amelioration effect achieved with the risperidone treatment (Ortega-Alvaro et al, 2011). In the case of the CNR1 gene, we found a different behavioral phenotype in CB1r knockout (CB1KO) mice. Although both mice share a PPI deficit of the acoustic startle response, the pharmacological studies carried out suggested that different neurobiological processes were involved.

The study of the distribution of parvalbumin (PV; basket and chandelier) and cholecystokinin-8 (CCK; basket) interneurons is relevant because both are fast-spiking GABAergic interneurons involved in the synchronization of pyramidal cell discharges (Cardin et al, 2009; Inda et al, 2009; LovettBarron and Losonczy, 2014; Somogyi and Klausberger, 2005). Cortical disinhibition is associated to preattentional deficits that are core symptoms of schizophrenia (Glausier et al, 2014; Lewis, 2014; Pezze et al, 2014; Volk and Lewis, 2014). However, recently altered GABAergic gene expression in ADHD children has also been reported (Wang et al, 2012), and alterations in PV-immunoreactive (PV-ir) neurons have been found in hypothyroid rats (Berbel et al, 1996), in humans suffering from epilepsy (DeFelipe, 2004), and in ASD patients (Berbel et al, 2014; Stoner et al, 2014). Recent studies have shown cortical inhibition altered in hypothyroid rats (Navarro et $a l, 2015)$ and in NMDAr ( $N$-methyl-Daspartate receptor) antagonist MK-801-treated mice (Gomes et al, 2014), both showing a reduction in the percentage of PPI. All these data strongly suggest that the analysis of the balance of excitatory to inhibitory inputs in the cerebral cortex is fundamental for the understanding of psychiatric disorders, most of them associated with developmental alterations during corticogenesis (Berbel et al, 2014; Volk and Lewis, 2014).

Overall, the main goal of this work was to study the preattentional deficit associated with CB1r deletion and its pharmacological modulation with antipsychotic (haloperidol or risperidone) or psychostimulant (methylphenidate) drugs. Furthermore, real-time PCR and immunohistochemical experiments were performed to analyze functional and structural alterations in the brain of CB1KO mice that could be associated with the impairment of the sensorimotor gating.

\section{MATERIALS AND METHODS}

\section{Animals}

Male cannabinoid receptor $\mathrm{CB} 1 \mathrm{KO}$ and WT mice were used in all of the experiments (for more details see Supplementary Information). All studies were conducted in compliance with the Spanish Royal Decree 53/2013 (BOE. 34) and the European Council Directive 2010/63/UE regulating the care of experimental animals.

\section{Drugs}

The atypical antipsychotic risperidone (STADA, Barcelona, Spain) was dissolved in sterile physiological saline and administered at doses of $1.5,3$, and $6 \mu \mathrm{g} / \mathrm{ml} / \mathrm{kg}$ (p.o.). The typical antipsychotic haloperidol (Esteve, Barcelona, Spain) was dissolved in sterile physiological saline and administered orally at doses of 1,3 , and $9 \mu \mathrm{g} / \mathrm{ml} / \mathrm{kg}$ (p.o.). The psychostimulant methylphenidate (Laboratorios Rubió, Barcelona, Spain) was dissolved in propylene glycol $1 \%$ and sterile physiological saline, and administered at doses of 50 , 100 , and $200 \mu \mathrm{g} / \mathrm{ml} / \mathrm{kg}$ (p.o.). The CB1r selective antagonist AM251 (Biogen, Madrid, Spain) was dissolved in DMSO, Tween-80, and sterile physiological saline in a proportion of $1: 1: 8$, respectively, and administered at doses of 100,200 , and $300 \mu \mathrm{g} / \mathrm{ml} / \mathrm{kg}$ (i.p.). All drugs were administered twice a day (0830 and $1800 \mathrm{~h})$.

\section{Sensorimotor Gating}

Acoustic PPI. PPI experiments were carried out in two steps. First, the PPI response was determined under baseline conditions in both CB1KO $(n=20)$ and WT $(n=14)$ mice. After confirming a significant difference in the PPI response, the effect of chronic oral treatment with risperidone, haloperidol, and methylphenidate (twice a day for 12 days) was evaluated in both CB1KO ( $n=8$ per group) and WT ( $n=8$ per group) mice. Animals were randomly assigned to each treatment group in each genotype. In addition, the effect of chronic intraperitoneal treatment with AM251 was evaluated in WT ( $n=8$ per group) mice. PPI response was evaluated after 4, 8, and 12 days of treatment. Startle 
responses were measured using the CIBERTEC REST 141 system (Madrid, Spain). More details about the apparatus and the PPI procedure are described in the Supplementary Information.

\section{Gene Expression Analyses}

Real-time PCR. Quantitative analysis of the relative abundance of $\alpha-2 \mathrm{C}$ adrenergic receptor (ADRA2C, Mm00431686_s1) in PFC and dopamine transporter (DAT, Mm00438388_m1) in VTA gene expressions was performed on the ABI PRISM 7700 Sequence Detector System (Applied Biosystems, Foster City, CA) between basal and methylphenidate-treated WT and $\mathrm{CB} 1 \mathrm{KO}$ mice. For more details see Supplementary Information.

\section{Immunohistochemical Analyses}

For PV-ir and CCK-ir cortical neuron quantitative analysis, we studied 5 mice per experimental group. In total, 10 sections per experimental group were analyzed (2 sections per mouse). Immunolabeled cells were counted in 10 probes ( $200 \mu \mathrm{m}$-wide; 1 probe/section), covering the central area of M2 and spanned from layer I to the subcortical white matter, as previously detailed (Figure 4; Berbel et al, 2001). The borders between layers and strata were placed at the same relative depth, as measured from adjacent neuronal nuclei (NeuN)-ir sections (Supplementary Figure S1). For each group the relative frequencies of immunolabeled cells per layer were averaged across probes and animals. Plots and counts of immunolabeled cells were obtained using the Cellgraph system (Microptic, Barcelona, Spain). For more details about the procedure of immunohistochemistry studies see Supplementary Information.

\section{Statistical Analyses}

See Supplementary Information for more details about statistical procedures.

\section{RESULTS}

\section{Assessment of Sensorimotor Gating between CB1KO and WT Mice}

CB1KO mice $(n=20)$ showed differences in the PPI of the acoustic startle response compared with WT mice $(n=14)$. One-way ANOVA with repeated measures revealed the significant main effects of genotype $\left(\mathrm{F}_{(1,32)}=23.183\right.$, $p<0.001)$ and prepulse intensity $\left(\mathrm{F}_{(2,32)}=76.244, p<0.001\right)$, whereas the genotype $\times$ prepulse intensity interaction was not significant $\left(\mathrm{F}_{(2,32)}=0.019, p=0.890\right.$; Figure 1$)$. Therefore, the reduction of PPI observed in CB1KO mice was independent of the prepulse intensity tested.

\section{Treatment with Risperidone on PPI in CB1KO and WT Mice: Time Course and Dose Response Effects}

The results obtained with risperidone treatment are shown in the Supplementary Table S1. The two-way ANOVA with repeated measures included two between-subject factors (genotype and drug treatment) and two within-subject

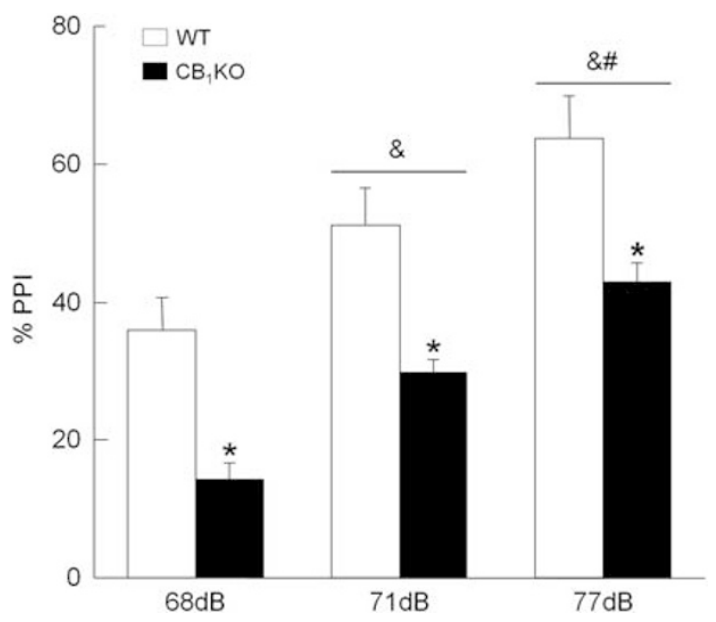

Figure I Prepulse inhibition of the acoustic startle response (I $20 \mathrm{~dB})$ was measured using 68, 7I, and $77 \mathrm{~dB}$ prepulse stimuli in $\mathrm{CBIKO}$ and WT mice. The columns represent the means and the vertical lines represent the \pm SEM of $\%$ prepulse inhibition. *Values from CBIKO mice that differ significantly from the values in WT mice (one-way ANOVA with repeated measures, genotype, $p<0.00 \mathrm{I}$ ); \& values that differ significantly from those obtained at $68 \mathrm{~dB}$; " values that differ significantly from those obtained at $7 \mathrm{I} \mathrm{dB}$ (one-way ANOVA with repeated measures, intensity, $p<0.00 \mathrm{I}$ ).

factors (prepulse intensity and time of treatment; Supplementary Table S2). From between factors, only the genotype produced significant differences in the PPI response between $\mathrm{CB} 1 \mathrm{KO}$ and $\mathrm{WT}$ mice $\left(\mathrm{F}_{(1,56)}=37.031\right.$, $p<0.001)$. Drug treatment and the genotype $\times$ drug treatment interaction were not significant. From within factors, the two factors of repetition, prepulse intensity and time of treatment, have emerged as relevant factors of variation. In the case of prepulse intensity a more intense prepulse induced a higher PPI value $\left(\mathrm{F}_{(1,56)}=333.519, p<0.001\right)$. In the case of time of treatment, as the treatment progresses, there is a decrease in PPI value $\left(\mathrm{F}_{(1,56)}=23.028, p<0.001\right)$. However, all interactions were not significant. In summary, risperidone treatment did not induce a significant effect on PPI response in $\mathrm{CB} 1 \mathrm{KO}$ or WT mice.

Treatment with Haloperidol on PPI in CB1KO and WT Mice: Time Course and Dose Response Effects

The results obtained with haloperidol treatment are shown in the Supplementary Table S3. The two-way ANOVA with repeated measures included two between-subject factors (genotype and drug treatment) and two within-subject factors (prepulse intensity and time of treatment; Supplementary Table S4). From between factors, only the genotype produced significant differences in the PPI response between $\mathrm{CB} 1 \mathrm{KO}$ and $\mathrm{WT}$ mice $\left(\mathrm{F}_{(1,56)}=24.244\right.$, $p<0.001)$. Drug treatment and the genotype $\times$ drug treatment interaction were not significant. From within factors, the two factors of repetition, time of treatment and prepulse intensity and the prepulse intensity $\times$ genotype interaction, have emerged as relevant factors of variation. In the case of time of treatment, as the treatment progresses, there is a decrease in PPI value $\left(\mathrm{F}_{(1,56)}=10.082, p<0.005\right)$. In the case of prepulse intensity a more intense prepulse induced a higher PPI value $\left(\mathrm{F}_{(1,56)}=155.318, p<0.001\right)$. In the case of prepulse intensity $\times$ genotype interaction, $\mathrm{CB} 1 \mathrm{KO}$ mice 

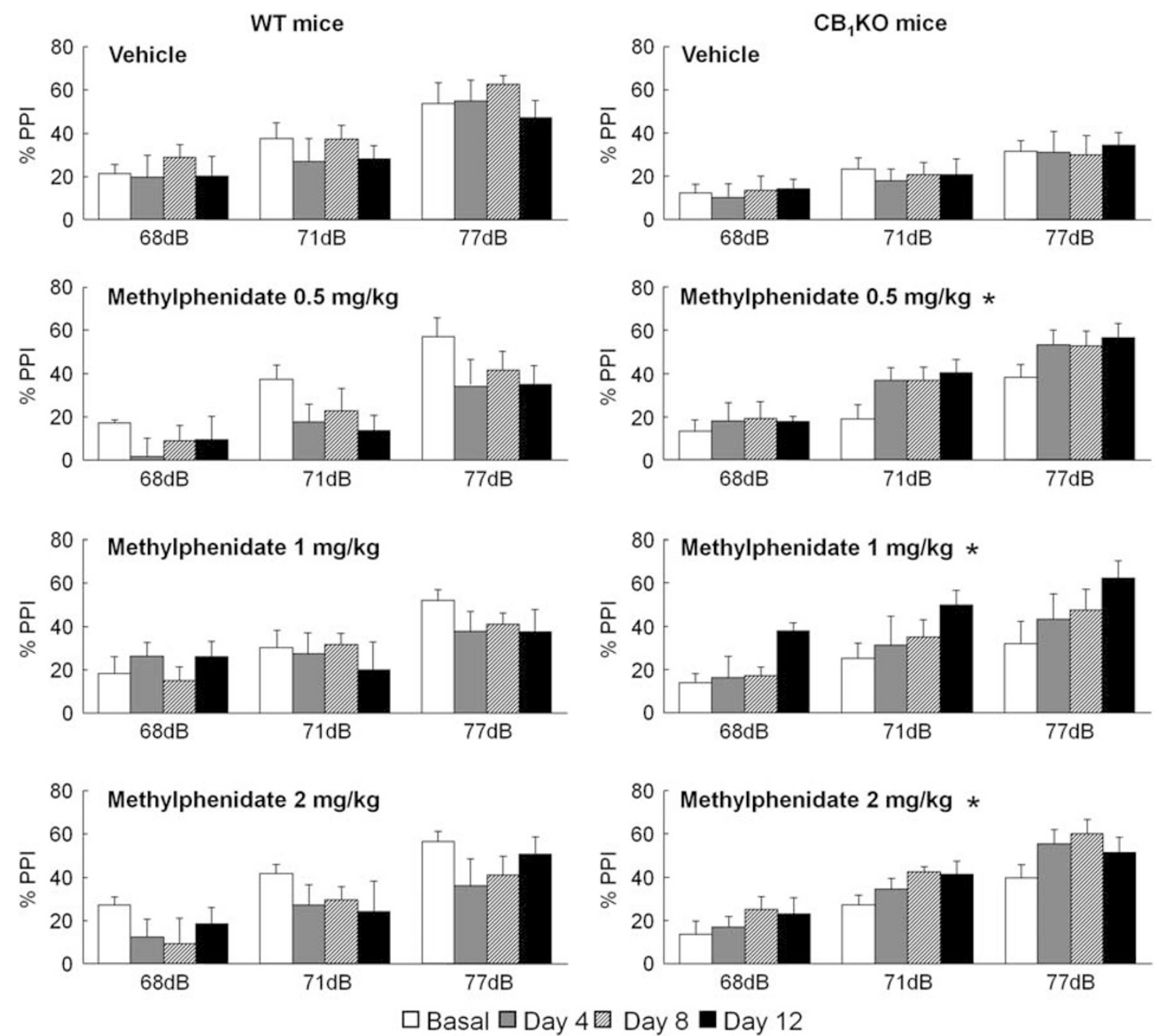

Figure 2 The effect of oral chronic treatment with methylphenidate on prepulse inhibition of the acoustic startle response was measured using 68, 7I, and $77 \mathrm{~dB}$ prepulse stimuli in CBIKO and WT mice. Determinations were performed before (baseline), and after 4, 8, and I2 days of treatment. Each panel corresponds with different groups of treatment with vehicle or methylphenidate $(0.5,1$, and $2 \mathrm{mg} / \mathrm{kg})$. The columns represent the means and the vertical lines represent the \pm SEM of \% prepulse inhibition. *Values that differ significantly from those obtained in vehicle-treated mice (two-way ANOVA with repeated measures, genotype $\times$ drug treatment, $p<0.05$ ).

showed a significantly reduced response in PPI compared with WT mice $\left(\mathrm{F}_{(1,56)}=12.434, p<0.005\right)$. However, the rest of interactions were not significant. In summary, haloperidol treatment did not induce a significant effect on PPI response in $\mathrm{CB} 1 \mathrm{KO}$ or WT mice.

\section{Treatment with Methylphenidate on PPI in CB1KO and WT Mice: Time Course and Dose Response Effects}

The results obtained with methylphenidate treatment are shown in Figure 2. The two-way ANOVA with repeated measures included two between-subject factors (genotype and drug treatment) and two within-subject factors (prepulse intensity and time of treatment; Table 1). From between factors, genotype and drug treatment were not significant. However, the genotype $\times$ drug treatment interaction produced significant differences in the PPI response between $\mathrm{CB} 1 \mathrm{KO}$ and $\mathrm{WT}$ mice $\left(\mathrm{F}_{(3,56)}=3.890, p<0.05\right)$. Thus, treatment with methylphenidate $(0.5,1$, and $2 \mathrm{mg} / \mathrm{kg})$ significantly increased PPI response in CB1KO compared with vehicle-treated mice, whereas there were no effects in vehicle-treated WT mice. From within factors, the two factors of repetition, time of treatment and prepulse intensity, the time of treatment $\times$ genotype and the prepulse intensity $\times$ genotype interactions, have emerged as relevant factors of variation. In the case of time of treatment, as the treatment progresses, there is an increase in PPI value $\left(\mathrm{F}_{(1,56)}=9.314, p<0.005\right)$. In the case of prepulse intensity a more intense prepulse induced a higher PPI value $\left(\mathrm{F}_{(1,56)}=32.720, p<0.001\right)$. In the case of time of treatment $x$ genotype interaction, CB1KO mice showed a significant increase in PPI response along the time of treatment, whereas WT mice did not show variations in its response $\left(\mathrm{F}_{(1,56)}=15.849, p<0.001\right)$. In the case of prepulse intensity $\times$ genotype interaction, CB1KO mice showed more intense PPI responses induced by higher prepulse intensities, whereas WT mice did not show a different response in correspondence to prepulse intensity variation $\left(\mathrm{F}_{(1,56)}=31.054, p<0.001\right)$. However, the rest of interactions were not significant. In summary, methylphenidate 
Table I Results of Two-Way ANOVA with Repeated Measures Performed on \%PPI in CBIKO and WT Mice Treated with Methylphenidate

\begin{tabular}{lrrr}
\hline Factors & df & F & P-value \\
\hline Between subject & & & \\
Genotype & 1,56 & 0.067 & 0.797 \\
Treatment & 3,56 & 0.773 & 0.514 \\
Genotype $\times$ treatment & 3,56 & 3.890 & $<0.050$ \\
& & & \\
Within subject & & & \\
Time & 1,56 & 9.314 & $<0.005$ \\
Time $\times$ genotype & 1,56 & 15.849 & $<0.001$ \\
Time $\times$ treatment & 3,56 & 2.421 & 0.075 \\
Time $\times$ genotype $\times$ treatment & 3,56 & 1.286 & 0.288 \\
Prepulse intensity & 1,56 & 32.720 & $<0.001$ \\
Prepulse intensity $\times$ genotype & 1,56 & 31.054 & $<0.001$ \\
Prepulse intensity $\times$ treatment & 3,56 & 0.110 & 0.954 \\
Prepulse intensity $\times$ genotype $\times$ treatment & 3,56 & 1.202 & 0.318 \\
Time $\times$ prepulse intensity & 1,56 & 0.064 & 0.802 \\
Time $\times$ prepulse intensity $\times$ genotype & 1,56 & 0.747 & 0.391 \\
Time $\times$ prepulse intensity $\times$ treatment & 3,56 & 1.129 & 0.345 \\
Time $\times$ prepulse intensity $\times$ genotype $\times$ treatment & 3,56 & 1.195 & 0.320 \\
\hline & & & \\
\hline
\end{tabular}

treatment induced a significant effect on PPI response in $\mathrm{CB} 1 \mathrm{KO}$, whereas it was without effect in WT mice.

\section{Treatment with AM251 on PPI in WT Mice: Time Course and Dose Response Effects}

The results obtained with AM251 treatment are shown in the Supplementary Table S5. The one-way ANOVA with repeated measures included one between-subject factors (drug treatment) and two within-subject factors (prepulse intensity and time of treatment; Supplementary Table S6). Drug treatment did not induce significant changes in PPI response in WT mice. From within factors, prepulse intensity and the prepulse intensity $\times$ drug treatment interaction have emerged as relevant factors of variation. In the case of prepulse intensity a more intense prepulse induced a higher PPI value $\left(F_{(1,28)}=409.826, p<0.001\right)$. In the case of prepulse intensity $\times$ drug treatment interaction, AM251 $(3 \mathrm{mg} / \mathrm{kg})$-treated mice showed a significant reduced response in PPI compared with vehicle-treated mice at 68 and $71 \mathrm{~dB}$ prepulse intensities $\left(\mathrm{F}_{(3,28)}=3.455, p<0.05\right)$. However, time of treatment and the rest of interactions were not significant. In summary, only $3 \mathrm{mg} / \mathrm{kg}$ AM251 treatment significantly reduced PPI response in WT mice at 68 and $71 \mathrm{~dB}$ prepulse intensities.

\section{Evaluation of ADRA2C and DAT Gene Expressions in CB1KO and WT Mice}

Real-time PCR analyses in basal conditions showed that there were no significant differences in the mRNA levels of ADRA2C in the PFC (Figure 3a, Student's $t$-test: $t=0.0863$, $19 \mathrm{df}, p=0.933$ ) and DAT in the VTA (Figure 3c, Student's $t$ -

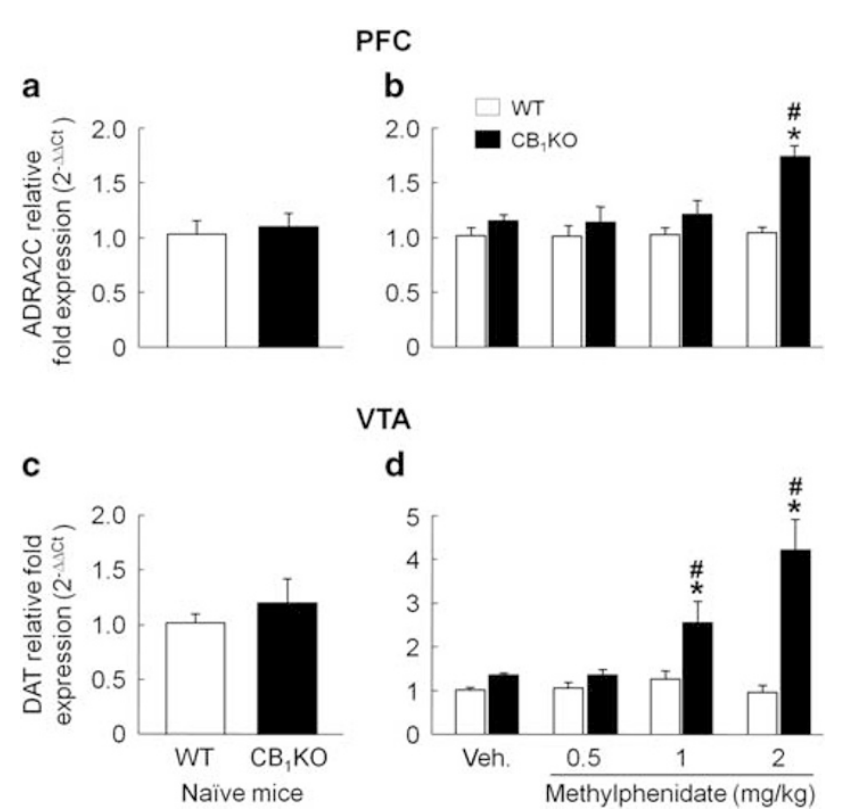

Figure 3 Real-time PCR analyses of ADRA2C and DAT relative gene expression between WT and CBIKO mice. Columns represent the means and vertical lines \pm SEM of relative gene expression evaluation $(2-\Delta \Delta C t$ method) in the PFC (a, b) and VTA (c, d). *Values of methylphenidatetreated CBIKO mice that are significantly different $(p<0.05)$ from vehicletreated WT mice; "\#alues of methylphenidate-treated CBIKO mice that are significantly different $(p<0.05)$ from vehicle-treated CBIKO mice.

test: $t=-0.0395,19 \mathrm{df}, p=0.969)$ between WT and CB1KO mice. Treatment with methylphenidate significantly upregulated ADRA2C (2 mg/kg dose, Figure 3b; two-way ANOVA, Genotype: $\mathrm{F}_{(1,74)}=1.368, p=0.249$; Treatment: $\mathrm{F}_{(3,74)}=3.125, \quad p=0.036 ; \quad$ and Genotype $\times$ Treatment interaction: $\left.\mathrm{F}_{(3,74)}=1.245 ; p=0.306\right)$ and DAT (1 and $2 \mathrm{mg} / \mathrm{kg}$ doses, Figure 3d; two-way ANOVA, Genotype: $\mathrm{F}_{(1,74)}=12.233, p<0.001$; Treatment: $\mathrm{F}_{(3,74)}=3.949, p<0.05$; and Genotype $\times$ Treatment interaction: $F_{(3,74)}=3.460$; $p<0.05)$ in $\mathrm{CB} 1 \mathrm{KO}$ mice, without producing changes in WT animals.

\section{Immunohistochemical Analyses of PV-ir and CCK-ir Cortical Neurons in CB1KO and WT Mice}

No statistically significant differences were found in the cortical layer thickness between WT and CB1KO mice. The total thickness of M2 was, on average, $1264 \pm 45 \mu \mathrm{m}$ in WT and $1283 \pm 63 \mu \mathrm{m}$ in $\mathrm{CB} 1 \mathrm{KO}$ mice. However, the border of layers II-III/V and V/VI was more blurred in CB1KO mice (Supplementary Figure S1). At a higher magnification, prominent perisomatic (Supplementary Figure S1C-F, arrows) and axon initial segment (Supplementary Figure S1F, arrowhead) PV-ir buttons were seen in both WT and $\mathrm{CB} 1 \mathrm{KO}$ mice. The radial distribution of PV-ir neurons in CB1KO mice was abnormal (Figure $4 \mathrm{a}$ and c). The PV-ir neuron percentage was greater in WT layers $\mathrm{V}(36.0 \pm 3.4 \%)$ and VI $(35.0 \pm 5.0 \%)$ and less $(p=0.029)$ in WT layers II-III $(27.4 \pm 4.8 \%)$. In contrast, $\mathrm{PV}$-ir neuron percentage was greater in $\mathrm{CB} 1 \mathrm{KO}$ layer VI $(45.6 \pm 2.9 \%)$ and significantly decreased $(P<0.001)$ in CB1KO layers $\mathrm{V}(33.8 \pm 3.8 \%)$ and II-III $(20.2 \pm 2.9 \%)$. It was $0.5 \pm 0.3$ and $0.3 \pm 0.5 \%$ in WT and CB1KO layer I, respectively (Supplementary Figure S2A). 
a

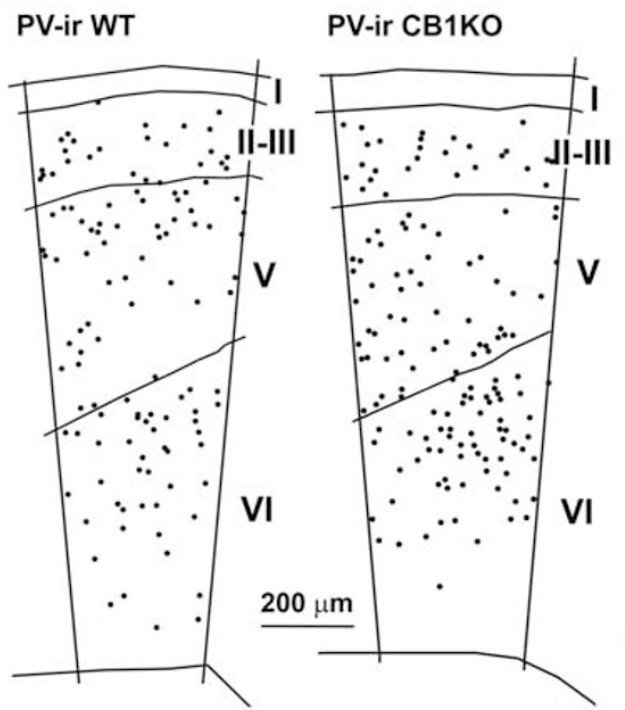

C

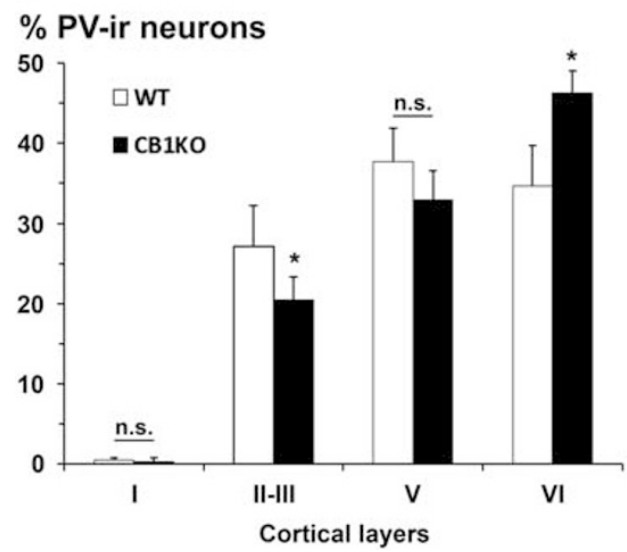

b

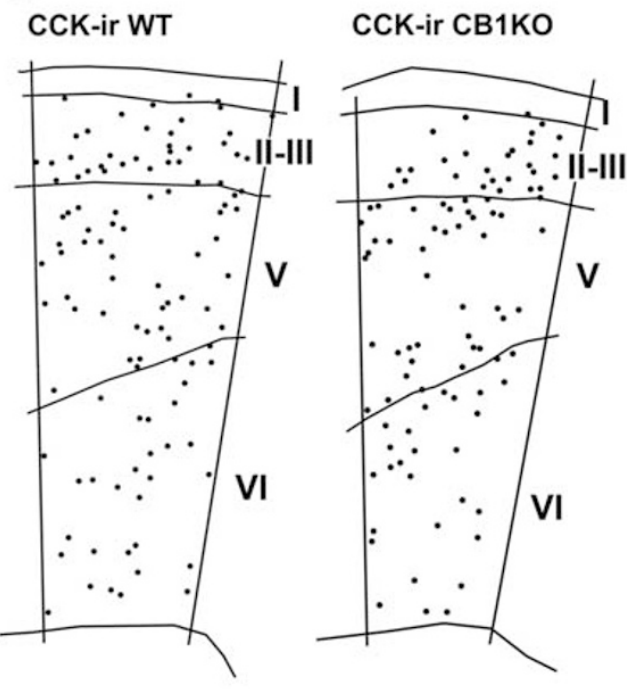

d

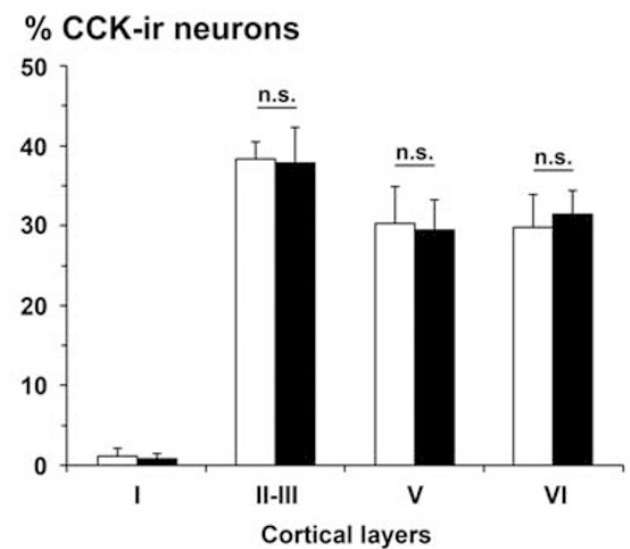

Figure 4 (a, b) Plots of coronal sections of the associative motor cortex (M2) showing the distribution of PV-ir (a) and CCK-ir (b) neurons in WT and CBIKO mice. (c, d) Histograms showing the percentage of PV-ir (c) and CCK-ir (d) neurons in different M2 layers of WT and CBIKO mice (see also Supplementary Figure 2). Note that the density of PV-ir neurons in CBI KO mice decreases in layers II-III and $\mathrm{V}$ and increases in layer $\mathrm{VI}$ compared with WT mice. No significant differences were found between CCK-ir neuron percentage among layers in WT and CBIKO mice (b, d). Error bars represent \pm SD across layers from the same group. n.s., no significant difference. *Significant difference $(p<0.05, n=10$ for each group).

Compared with WT mice, PV-ir neuron percentage decreased $(p=0.021)$ in CB1KO layers II-III and increased $(p=0.04)$ in layer VI (Figure $4 c$ and Supplementary Figure S2A).

No significant differences between WT and CB1KO mice were found in the radial distribution of CCK-ir neurons (Figure $4 \mathrm{~b}$ and $\mathrm{d}$ ). In both groups, the CCK-ir neuron percentage was greater in WT and $\mathrm{CB} 1 \mathrm{KO}$ layers II-III $(38.5 \pm 2.2$ and $38.0 \pm 4.0 \%$, respectively) and less $(P<0.01)$ in WT and CB1KO layers $\mathrm{V}(30.4 \pm 4.7$ and $29.5 \pm 3.5 \%$, respectively) and VI $(29.9 \pm 4.1$ and $31.6 \pm 2.6 \%$, respectively). It was $1.2 \pm 1.0$ and $0.9 \pm 0.7 \%$ in WT and $\mathrm{CB} 1 \mathrm{KO}$ layer I, respectively (Supplementary Figure S2B).

\section{DISCUSSSION}

The results obtained in this study suggest that CB1r deletion induces a preattentional deficit, emphasizing the important role of $\mathrm{CB} 1 \mathrm{r}$ in sensorimotor gating modulation. This assumption is supported by the following findings: (1) CB1KO mice have significantly lower PPI values than WT mice, (2) treatment with the CB1r antagonist AM251 (3 mg/ $\mathrm{kg}$ ) produces an impairment of PPI in WT mice, (3) typical and atypical antipsychotics (risperidone and haloperidol, respectively) did not ameliorate PPI deficit in CB1KO mice, (4) treatment with the psychostimulant methylphenidate significantly improved PPI in $\mathrm{CB} 1 \mathrm{KO}$ and this effect was accompanied by gene expression regulation of ADRA2C and DAT in the PFC and VTA, respectively, and (5) NeuN immunolabeling showed blurred borders between layers in $\mathrm{CB} 1 \mathrm{KO}$ mice and the radial distribution of $\mathrm{PV}$-ir neurons was abnormal in CB1KO mice.

Previous studies have evaluated the role of the endocannabinoid system (ECS) signaling in sensorimotor gating regulation, suggesting a role of CB1r in psychiatric disorders characterized by a preattention deficit. Chronic stimulation of the ECS by $\Delta 9$-THC, synthetic agonists (WIN55,212-2 and $\mathrm{CP}-55,940$ ), or through the activation of endogenous 
cannabinoids release (anandamide) induced a disruption of PPI (Fernandez-Espejo and Galan-Rodriguez, 2004; Hajos et al, 2008; Malone and Taylor, 2006; Schneider and Koch, 2002). Importantly, this effect could be completely reversed with CB1r antagonists (SR141716 and AM251), suggesting that the PPI impairment in these experimental conditions is selectively mediated by CB1r. A plausible explanation for this effect may be that the long-term maintained activation could promote compensatory mechanisms leading to a downregulation of functional CB1r that in turn might trigger sensorimotor gating deficits. This hypothesis is sustained by several observations indicating that lower or absent CB1r function is closely related with the presence of PPI deficits. A study with pharmacologically inducible and reversible tissuespecific CB1KO mice showed a PPI deficit only under doxycycline-induced ablation of CB1r gene expression (Marongiu et al, 2012). However, no differences in PPI response were found between $\mathrm{CB} 1 \mathrm{KO}$ and WT mice. In contrast, the results of the present study clearly revealed lower PPI in CB1KO mice at 68, 71, and $77 \mathrm{~dB}$ prepulse sound levels. These discrepancies could be attributed to different genetic manipulation processes to obtain the deletion of CB1r and, most probably, to the use of mice with different genetic backgrounds (CBA/J-C57BL/10 and CD1 strains). In addition, another study showed that the CB1r antagonist rimonabant (SR141716, $0.75 \mathrm{mg} / \mathrm{kg}$ ) significantly reduced PPI in SHR rats (Levin et al, 2014). Accordingly, in the present study WT mice treated with the highest dose of AM251 (3 mg/kg) showed significantly lower PPI in comparison with control animals (see Supplementary Tables S5 and S6).

Sensorimotor gating alterations, present in schizophrenia, have been associated with dopaminergic hyperactivity. Several studies in animal models have demonstrated that dopaminergic activation (eg, apomorphine treatment, deletion of DAT) induces PPI disruption that is blocked by dopaminergic antagonists such as typical or atypical antipsychotics (Swerdlow and Geyer, 1993). In our study, treatment with risperidone or haloperidol did not modify PPI values in CB1KO mice, whereas a tendency toward an impairment effect was obtained in WT mice as shown previously (Ortega-Alvaro et al, 2011). Interestingly, the administration of the psychostimulant methylphenidate significantly improved PPI in CB1KO mice.

Previous studies suggested that ADRA2C receptors were critically involved in the modulation of acoustic startle reflex and, therefore, in sensorimotor gating measured by the PPI paradigm. A targeted inactivation (knockout) of ADRA2C receptors in mice produced PPI deficits that were completely abolished with a tissue-specific overexpression (Sallinen et al, 1998). Several studies revealed that methylphenidate therapeutic usefulness is in part because of the activation of ADRA2 receptors (Andrews and Lavin, 2006). In the present study, there were not gene expression differences in ADRA2C receptors between $\mathrm{WT}$ and $\mathrm{CB} 1 \mathrm{KO}$ mice (basal conditions), whereas treatment with $2 \mathrm{mg} / \mathrm{kg}$ methylphenidate significantly upregulated the expression of this receptor gene in CB1KO mice that could be related with the improvement of PPI. On the other hand, it is widely known that the main mechanism of action of methylphenidate is the increase of dopamine concentrations because of blockade of DAT. This effect was associated with increased DAT gene expression found in the CB1KO mice treated with methylphenidate. Noteworthy, this effect is not only associated with the therapeutic usefulness of methylphenidate, but also with the possible development of drug addiction problems (Calipari et al, 2013; Somkuwar et al, 2013). In conclusion, the improvement of PPI deficits in CB1KO mice by methylphenidate may be related with the regulation of ADRA2C and DAT gene expressions in CB1KO mice, but not in WT mice.

PV and CCK markers were selected because PV-ir and CCK-ir neurons are the two major, non-overlapping types of GABAergic basket neurons in the rat neocortex (Kawaguchi and Kubota, 1997). Another type of GABAergic neurons are the PV-ir chandelier cells that synapse the axon initial segment of the pyramidal neurons (Inda et al, 2009). Recent data show that migrating neurons express CB1r during neocorticogenesis and that the endocannabinoid signaling control not only pyramidal positioning but also long-range axon patterning (Berghuis et al, 2007; Mulder et al, 2008; Oudin et al, 2011). Interestingly, in CB1KO mice, the density of pyramidal neurons in superficial layers decreased whereas it increased in deep cortical layers as a result of abnormal radial migration (Mulder et al, 2008). Abnormal radial migration also causes blurred layering in the neocortex (Berbel et al, 2001). In agreement, our results show that in $\mathrm{CB} 1 \mathrm{KO}$ mice the borders between layers are blurred and the radial distribution of $\mathrm{PV}$-ir neurons is altered. In comparison with WT mice, the PV-ir neuron percentage decreases in layers II-III and increases in layer VI. As the tangential migration of $\mathrm{PV}$-ir neurons precedes the radial positioning of their target pyramidal neurons, it is very likely that the abnormal distribution of PV-ir neurons might be as a consequence of the abnormal radial migration of pyramidal target cells, more than a consequence of their abnormal tangential PV-ir cell migration, although the latter should not be excluded. We have shown that PV-ir neuron distribution is abnormal, as it is the CCK modulatory function, because they do not express CB1r. These alterations might alter the synchrony of firing pattern of pyramidal target neurons.

Overall, this study adds new information about the pivotal role of $\mathrm{CB} 1 \mathrm{r}$ in the regulation of sensorimotor gating processes and demonstrates that the preattentional deficit showed by CB1KO mice could be improved by methylphenidate but not with haloperidol or risperidone administration. Future studies are encouraged to further evaluate the possible therapeutic usefulness of methylphenidate and CB1r pharmacological regulation in the management of psychiatric disorders presenting preattentional deficits.

\section{FUNDING AND DISCLOSURE}

The authors declare no conflict of interest.

\section{ACKNOWLEDGMENTS}

We thank Raquel Poveda for the excellent technical assistance. This study was supported by the following research grants: Ministerio de Ciencia e Innovación SAF2011-23420 to Jorge Manzanares and SAF2009-10689 to Pere Berbel; Foundation Alicia Koplowitz to Pere Berbel; and Instituto de Salud 'Carlos 
III' (FIS), RETICS, Red de Trastornos Adictivos (RD06/0001/ 1004, RD12/0028/0019) to Jorge Manzanares.

\section{REFERENCES}

Andrews GD, Lavin A (2006). Methylphenidate increases cortical excitability via activation of alpha-2 noradrenergic receptors. Neuropsychopharmacology 31: 594-601.

Berbel P, Auso E, Garcia-Velasco JV, Molina ML, Camacho M (2001). Role of thyroid hormones in the maturation and organisation of rat barrel cortex. Neuroscience 107: 383-394.

Berbel P, Marco P, Cerezo JR, DeFelipe J (1996). Distribution of parvalbumin immunoreactivity in the neocortex of hypothyroid adult rats. Neurosci Lett 204: 65-68.

Berbel P, Navarro D, Román G (2014). An evo-devo approach to thyroid hormones in cerebral and cerebellar cortical development: etiological implications for autism. Front Endocrinol 5: 146.

Berghuis P, Rajnicek AM, Morozov YM, Ross RA, Mulder J, Urban GM et al (2007). Hardwiring the brain: endocannabinoids shape neuronal connectivity. Science 316: 1212-1216.

Calipari ES, Ferris MJ, Salahpour A, Caron MG, Jones SR (2013). Methylphenidate amplifies the potency and reinforcing effects of amphetamines by increasing dopamine transporter expression. Nat Commun 4: 2720.

Cardin JA, Carlen M, Meletis K, Knoblich U, Zhang F, Deisseroth K et al (2009). Driving fast-spiking cells induces gamma rhythm and controls sensory responses. Nature 459: 663-667.

Castellanos FX, Fine EJ, Kaysen D, Marsh WL, Rapoport JL, Hallett M (1996). Sensorimotor gating in boys with Tourette's syndrome and ADHD: preliminary results. Biol Psychiatry 39: 33-41.

Conzelmann A, Pauli P, Mucha RF, Jacob CP, Gerdes AB, Romanos J et al (2010). Early attentional deficits in an attention-to-prepulse paradigm in ADHD adults. J Abnorm Psychol 119: 594-603.

Dawson ME, Hazlett EA, Filion DL, Nuechterlein KH, Schell AM (1993). Attention and schizophrenia: impaired modulation of the startle reflex. J Abnorm Psychol 102: 633-641.

DeFelipe J (2004). Cortical microanatomy and human brain disorders: epilepsy. Cortex 40: 232-233.

Feifel D, Minassian A, Perry W (2009). Prepulse inhibition of startle in adults with ADHD. J Psychiatr Res 43: 484-489.

Fernandez-Espejo E, Galan-Rodriguez B (2004). Sensorimotor gating in mice is disrupted after AM404, an anandamide reuptake and degradation inhibitor. Psychopharmacology (Berl) 175: 220-224.

Glausier JR, Fish KN, Lewis DA (2014). Altered parvalbumin basket cell inputs in the dorsolateral prefrontal cortex of schizophrenia subjects. Mol Psychiatry 19: 30-36.

Gomes FV, Issy AC, Ferreira FR, Viveros MP, Del Bel EA, Guimaraes FS (2014). Cannabidiol attenuates sensorimotor gating disruption and molecular changes induced by chronic antagonism of NMDA receptors in mice. Int J Neuropsychopharmacol 18.

Hajos M, Hoffmann WE, Kocsis B (2008). Activation of cannabinoid1 receptors disrupts sensory gating and neuronal oscillation: relevance to schizophrenia. Biol Psychiatry 63: 1075-1083.

Hanlon MC, Karayanidis F, Schall U (2009). Intact sensorimotor gating in adult attention deficit hyperactivity disorder. Int $J$ Neuropsychopharmacol 12: 701-707.

Heekeren K, Meincke U, Geyer MA, Gouzoulis-Mayfrank E (2004). Attentional modulation of prepulse inhibition: a new startle paradigm. Neuropsychobiology 49: 88-93.

Inda MC, DeFelipe J, Munoz A (2009). Morphology and distribution of chandelier cell axon terminals in the mouse cerebral cortex and claustroamygdaloid complex. Cereb Cortex 19: 41-54.

Kawaguchi Y, Kubota Y (1997). GABAergic cell subtypes and their synaptic connections in rat frontal cortex. Cereb Cortex 7: 476-486.
Kedzior KK, Martin-Iverson MT (2006). Chronic cannabis use is associated with attention-modulated reduction in prepulse inhibition of the startle reflex in healthy humans. J Psychopharmacol 20: 471-484.

Kohl S, Heekeren K, Klosterkotter J, Kuhn J (2013). Prepulse inhibition in psychiatric disorders-apart from schizophrenia. J Psychiatr Res 47: 445-452.

Leroy S, Griffon N, Bourdel MC, Olie JP, Poirier MF, Krebs MO (2001). Schizophrenia and the cannabinoid receptor type 1 (CB1): association study using a single-base polymorphism in coding exon 1. Am J Med Genet 105: 749-752.

Levin R, Peres FF, Almeida V, Calzavara MB, Zuardi AW, Hallak JE et al (2014). Effects of cannabinoid drugs on the deficit of prepulse inhibition of startle in an animal model of schizophrenia: the SHR strain. Front Pharmacol 5: 10.

Lewis DA (2014). Inhibitory neurons in human cortical circuits: substrate for cognitive dysfunction in schizophrenia. Curr Opin Neurobiol 26: 22-26.

Lovett-Barron M, Losonczy A (2014). Behavioral consequences of GABAergic neuronal diversity. Curr Opin Neurobiol 26: 27-33.

Malone DT, Taylor DA (2006). The effect of Delta9tetrahydrocannabinol on sensorimotor gating in socially isolated rats. Behav Brain Res 166: 101-109.

Marongiu MF, Poddie D, Porcu S, Manchinu MF, Castelli MP, Sogos V et al (2012). Reversible disruption of pre-pulse inhibition in hypomorphic-inducible and reversible CB1-/- mice. PLoS One 7: e35013.

Martin RS, Secchi RL, Sung E, Lemaire M, Bonhaus DW, Hedley LR et al (2003). Effects of cannabinoid receptor ligands on psychosisrelevant behavior models in the rat. Psychopharmacology (Berl) 165: 128-135.

Mulder J, Aguado T, Keimpema E, Barabas K, Ballester Rosado CJ, Nguyen L et al (2008). Endocannabinoid signaling controls pyramidal cell specification and long-range axon patterning. Proc Natl Acad Sci U S A 105: 8760-8765.

Navarro D, Alvarado M, Navarrete F, Giner M, Obregon MJ, Manzanares J et al (2015). Gestational and early postnatal hypothyroidism alters VGluT1 and VGAT bouton distribution in the neocortex and hippocampus, and behavior in rats. Front Neuroanat 9: 9.

Ornitz EM, Hanna GL, de Traversay J (1992). Prestimulationinduced startle modulation in attention-deficit hyperactivity disorder and nocturnal enuresis. Psychophysiology 29: 437-451.

Ornitz EM, Russell AT, Hanna GL, Gabikian P, Gehricke JG, Song D et al (1999). Prepulse inhibition of startle and the neurobiology of primary nocturnal enuresis. Biol Psychiatry 45: 1455-1466.

Ortega-Alvaro A, Aracil-Fernandez A, Garcia-Gutierrez MS, Navarrete F, Manzanares J (2011). Deletion of CB2 cannabinoid receptor induces schizophrenia-related behaviors in mice. Neuropsychopharmacology 36: 1489-1504.

Oudin MJ, Hobbs C, Doherty P (2011). DAGL-dependent endocannabinoid signalling: roles in axonal pathfinding, synaptic plasticity and adult neurogenesis. Eur J Neurosci 34: 1634-1646.

Pezze M, McGarrity S, Mason R, Fone KC, Bast T (2014). Too little and too much: hypoactivation and disinhibition of medial prefrontal cortex cause attentional deficits. I Neurosci 34: 7931-7946.

Rubino T, Parolaro D (2014). Cannabis abuse in adolescence and the risk of psychosis: a brief review of the preclinical evidence. Prog Neuropsychopharmacol Biol Psychiatry 52: 41-44.

Sallinen J, Haapalinna A, Viitamaa T, Kobilka BK, Scheinin M (1998). Adrenergic alpha2C-receptors modulate the acoustic startle reflex, prepulse inhibition, and aggression in mice. J Neurosci 18: 3035-3042.

Schneider M, Koch M (2002). The cannabinoid agonist WIN $55,212-2$ reduces sensorimotor gating and recognition memory in rats. Behav Pharmacol 13: 29-37. 
Schulz-Juergensen S, Thiemann A, Gebhardt J, Baumgarten-Walczak A, Eggert P (2014). Prepulse inhibition of acoustic startle and the influence of methylphenidate in children with ADHD. J Atten Disord 18: 117-122.

Somkuwar SS, Darna M, Kantak KM, Dwoskin LP (2013). Adolescence methylphenidate treatment in a rodent model of attention deficit/ hyperactivity disorder: dopamine transporter function and cellular distribution in adulthood. Biochem Pharmacol 86: 309-316.

Somogyi P, Klausberger T (2005). Defined types of cortical interneurone structure space and spike timing in the hippocampus. J Physiol 562: 9-26.

Stoner R, Chow ML, Boyle MP, Sunkin SM, Mouton PR, Roy S et al (2014). Patches of disorganization in the neocortex of children with autism. N Engl J Med 370: 1209-1219.

Strauss ME (1993). Relations of symptoms to cognitive deficits in schizophrenia. Schizophr Bull 19: 215-231.

Swerdlow NR, Geyer MA (1993). Clozapine and haloperidol in an animal model of sensorimotor gating deficits in schizophrenia. Pharmacol Biochem Behav 44: 741-744.
Swerdlow NR, Geyer MA, Braff DL (2001). Neural circuit regulation of prepulse inhibition of startle in the rat: current knowledge and future challenges. Psychopharmacology (Berl) 156: 194-215.

Uriguen L, Garcia-Fuster MJ, Callado LF, Morentin B, La Harpe R, Casado $\mathrm{V}$ et al (2009). Immunodensity and mRNA expression of $\mathrm{A} 2 \mathrm{~A}$ adenosine, D2 dopamine, and CB1 cannabinoid receptors in postmortem frontal cortex of subjects with schizophrenia: effect of antipsychotic treatment. Psychopharmacology (Berl) 206: 313-324.

Volk DW, Lewis DA (2014). Early developmental disturbances of cortical inhibitory neurons: contribution to cognitive deficits in schizophrenia. Schizophr Bull 40: 952-957.

Wang LJ, Huang YS, Hsiao CC, Chen CK (2012). The trend in morning levels of salivary cortisol in children with ADHD during 6 months of methylphenidate treatment. J Atten Disord (in press).

Zavitsanou K, Garrick T, Huang XF (2004). Selective antagonist [3H]SR141716A binding to cannabinoid CB1 receptors is increased in the anterior cingulate cortex in schizophrenia. Prog Neuropsychopharmacol Biol Psychiatry 28: 355-360.

Supplementary Information accompanies the paper on the Neuropsychopharmacology website (http://www.nature.com/npp) 